Trivent Publishing

(C) The Authors, 2016

Available online at http://trivent-publishing.eu/

Engineering and Industry Series

Volume Power Systems, Energy Markets and Renewable Energy Sources in

South-Eastern Europe

\title{
The Study and Evaluation of the 3phase Induction Motor Controlled by an Inverter to Identify Power Losses and Energy Saving
}

\author{
Lamas G., ${ }^{1}$ Syllignakis J., ${ }^{2}$ Karapidakis E. ${ }^{3}$ \\ ${ }^{1}$ Technological Educational Institution of Crete (TEIC), School of Engineering, \\ Department of Electrical Engineering, Greece \\ ${ }^{2}$ Technological Educational Institution of Crete (TEIC), School of Applied Sciences, \\ Department of Environmental and Natural Resources Engineering, Greece \\ ${ }^{3}$ Technical University of Crete (TUC), School of Production \\ Engineering and Management, Greece
}

\begin{abstract}
The control of induction motors through an inverter has many advantages. By changing the frequency and size of the supply voltage, a better efficiency at load conditions can be achieved outside the rated operation. In this study, tests were conducted on a laboratory device for a three-phase induction motor of $1 \mathrm{Hp}$ capacity that was driven by an inverter. The induction machine loading was done via a magnetic brakes machine, while all the necessary measuring devices were used in order to record the necessary electrical magnitudes with accuracy and detail. Through specific tests, the components of the detailed electrical equivalent circuit were determined. The vector control technique was used on inverter operation. Through this study, the authors concluded that a drive system can be driven on different frequency levels without a great loss of torque. Furthermore, energy can be saved by operating in lower frequencies for smaller loading, having an equally satisfactory level of performance. It is also worth to mention the friendliness of the inverter to control the motor speed, the smooth (soft) starting and the high degree of efficiency in all frequency ranges.
\end{abstract}

This is an Open Access article distributed in accordance with the Creative Commons Attribution Non Commercial (CC-BY-NC-ND 4.0) license, which permits others to copy or share the article, provided original work is properly cited and that this is not done for commercial purposes. Users may not remix, transform, or build upon the material and may not distribute the modified material (http://creativecommons.org/licenses/by-nc/4.0/) 


\section{Keywords}

Induction motor drives; electrical machines; efficient operation of electrical machines

\section{Introduction}

Three-phase squirrel-cage induction motors are widely used in industrial drives because they are rugged, reliable and economical. Although traditionally used in fixed-speed service, induction motors are increasingly being used with variablefrequency drives (VFDs) in variable-speed service.

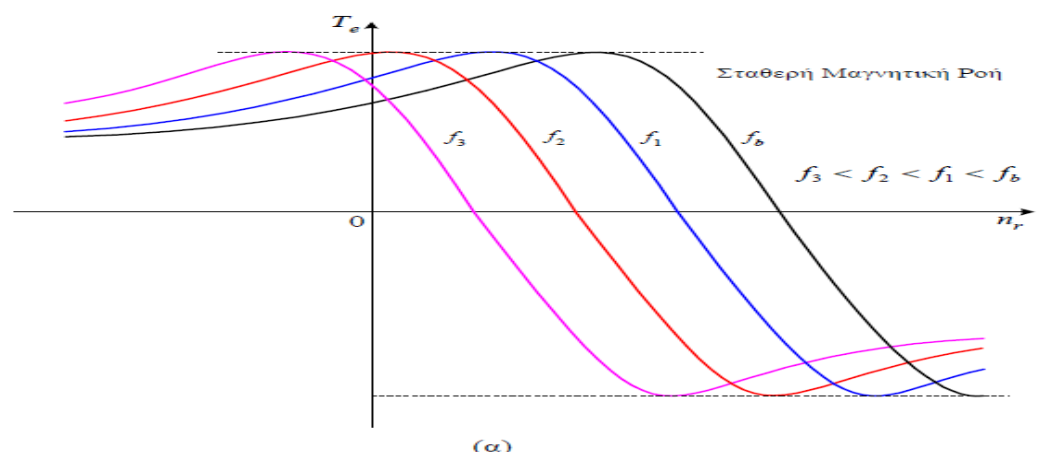

Fig. 1. Torque to frequency

VFDs offer especially important energy-saving opportunities for existing and prospective induction motors in variable-torque centrifugal fan, pump and compressor load applications. Squirrel cage induction motors are widely used in both fixed-speed and variable-frequency drive (VFD) applications. Variable voltage and variable frequency drives are also used in variable-speed service.

It is estimated that more than $50 \%$ of the world electric power is consumed by induction motors. Improving the efficiency in electric drives is very important, both for economic saving and for the reduction of environmental pollution $[1,2]$. Even though induction motors have a high efficiency at rated speed and torque, at low loading motor efficiency decreases dramatically due to an imbalance between the copper and the core losses. Hence, energy saving can be achieved by controlling the flux level in the motor $[3,4]$. The main induction motor losses are usually split into: stator copper losses, rotor copper losses, core (iron) losses, mechanical and stray losses. To improve the motor efficiency, the flux must be reduced, obtaining a balance between copper and core losses. Induction motor drive can be controlled according to a number of performance functions, such as input power, speed, torque, airgap flux, power factor, stator current, stator voltage, and overall efficiency [5].

Full load motor efficiency varies from about $85 \%$ to $97 \%$, related motor losses being broken down roughly as follows: 
- Friction and windage, $5 \%-15 \%$

- Iron or core losses, $15 \%-25 \%$

- Stator losses, $25 \%-40 \%$

- Rotor losses, $15 \%-25 \%$

- Stray load losses, $10 \%-20 \%$.

\section{Method}

A small industrial three-phase induction motor was tested in the laboratory. The topology of the electric circuit is shown below:

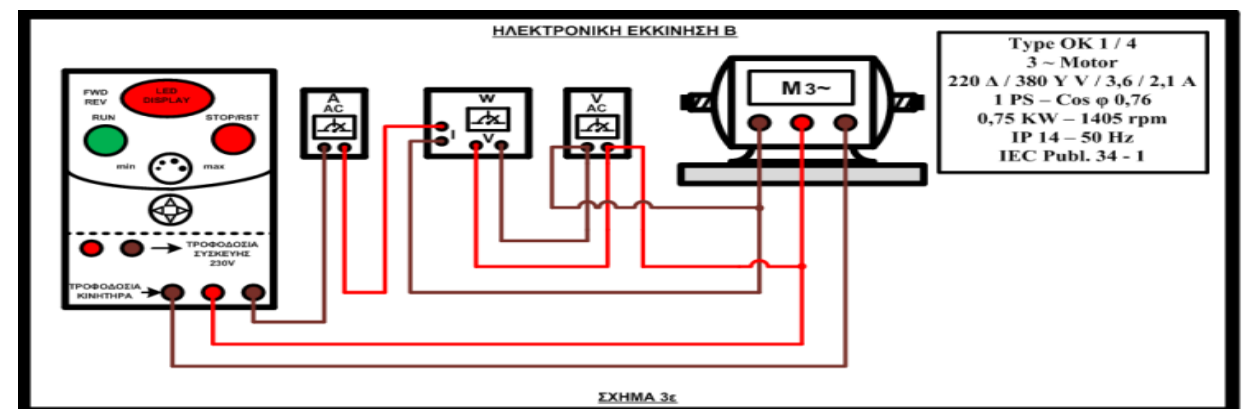

Fig. 2. Equivalent connection diagram for the experimental setup

In order to test the motor in loading, an electromagnetic breaking system on the axle was used, as shown in the picture below.

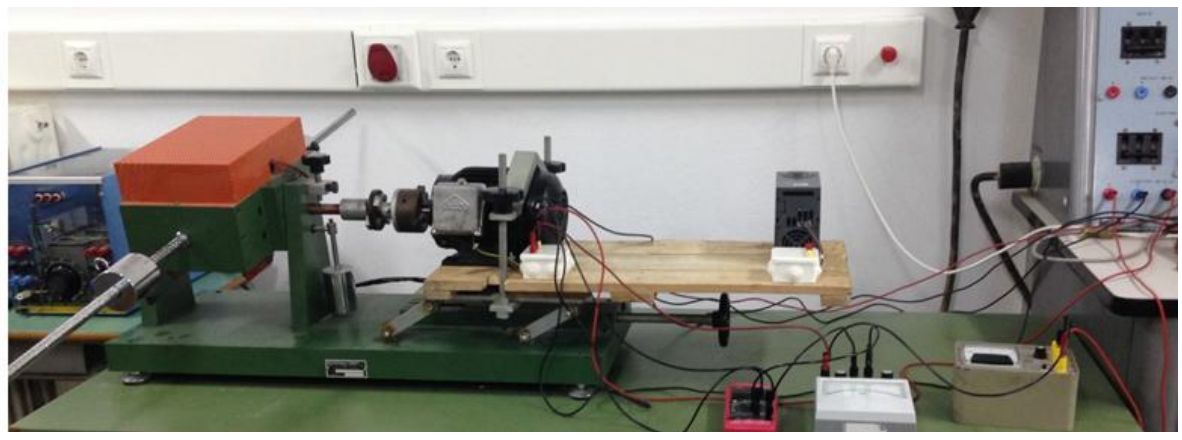

Fig. 3. Experimental setup. In this assembly, it is very helpful that also the torque can be calculated with a satisfying accuracy

\section{Mathematical modeling}

For the analysis of the operation of the ac motor the well known single-phase equivalent electric circuit was used [6]. 

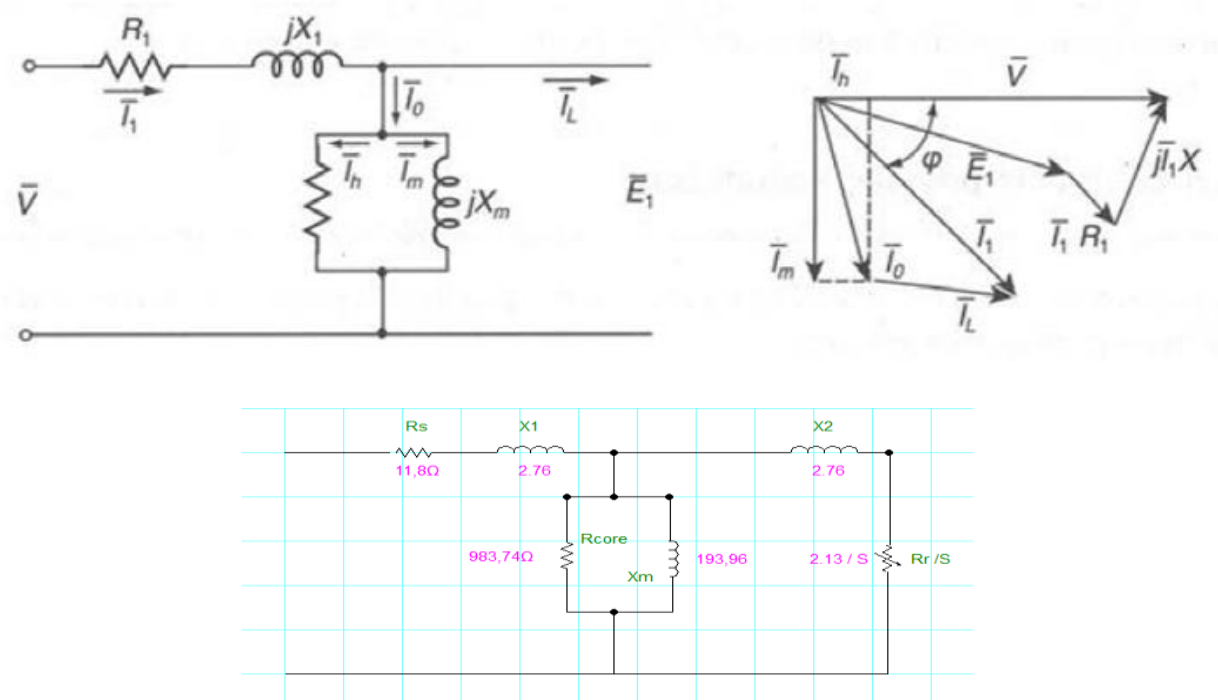

Fig. 4. Equivalent single-phase electrical circuit for the induction motor of out tests

The parameters of the circuit were calculated through the locked rotor and open no load test of the motor.

$$
\begin{gathered}
\mathrm{Rs}=11.8 \Omega \\
\mathrm{R}_{\mathrm{r}}=2.13 \Omega \\
\mathrm{X}=\mathrm{Xs}=\mathrm{Xr} \\
\mathrm{L}=\frac{\mathrm{x}}{2 \pi \mathrm{f}}=0.0088 \mathrm{H} \\
\mathrm{Rcore}=983,74 \Omega \\
\mathrm{X}_{\mathrm{m}}=193,96 \\
V_{1}=I_{1}\left(R_{1}+j X_{1}\right)+E_{1} \leq> \\
V_{1}=\left(I_{0}+I_{L}\right)\left(R_{1}+j X_{1}\right)+E_{1}
\end{gathered}
$$

Where:

$I_{1}:$ rms value of phase current (A)

$R_{1}$ : resistant of phase stator winding $\operatorname{Rs}(\Omega)$

$X_{1}=2 \pi f 1 L_{1}$ : inductance of phase stator winding $(\Omega)$

$I_{L}$ : load current (A)

$E_{1}:$ induced EMF per phase in stator winding

Also

where:

$$
I_{0}=I_{m}+I_{h}
$$


$I_{m}:$ magnitude current $(\mathrm{A})$

$I_{h}:$ hysteresis and dynes current $(\mathrm{A})$

In rotor:

$$
\begin{gathered}
E_{2 s}=4.44 K_{2} f_{2} N_{2} \Phi_{\delta \iota \alpha \kappa} \\
E_{2 s}=I_{2}\left(r_{2}+j 2 \pi f_{2} L_{2}\right)=I_{2}\left(r_{2}+j s x_{2}\right)
\end{gathered}
$$

where:

$\mathrm{I}_{2}$ : per phase rotor current (A)

$r_{2}$ : per phase resistance $(\Omega)$

$L_{2}, x_{2}$ : inductance of phase in rotor winding $(\mathrm{H}, \Omega)$

$s x_{2}$ : inductance on rotor frequency $(\Omega)$

Also:

$$
\begin{gathered}
n_{s}=120 \frac{f_{1}}{P} \\
\omega_{s}=2 \pi \frac{n_{s}}{60}=\frac{2}{P} 2 \pi f_{1}=\frac{2}{P} \omega_{1} \\
S=\frac{n_{s}-n_{r}}{n_{s}} \text { or } S(\%)=\frac{n_{s}-n_{r}}{n_{s}} \times 100 \text { or }, S=\frac{\omega_{s}-\omega_{r}}{\omega_{r}} \\
f_{2}=\frac{P}{2} \frac{\left(n_{s}-n_{r}\right)}{60}=\frac{P}{2} S \frac{n_{s}}{60}=S f_{1}
\end{gathered}
$$

Power loss in ac induction motors:

There are electrical $(\mathrm{Cu})$, magnetic (iron) and mechanical power losses:

$$
\begin{gathered}
\text { Stator: } P_{\text {iron (s) }}=k_{e} \omega^{2}{ }_{e} \Phi_{m}^{2}+k_{h} \omega_{e} \Phi_{m}^{n} \\
\text { Roror: } P_{\text {iron }(r)}=k_{e}\left(s \omega_{e}\right)^{2} \Phi_{m}{ }^{2}+k_{h} s \omega_{e} \Phi_{m}^{n}
\end{gathered}
$$

where $\mathrm{Ke}=$ machine constant,

$\Phi_{m}=$ magnetic flow

$\omega_{e}=$ radial speed

$$
P_{\text {iron }(s+r)}=\left[k_{e}\left(1+s^{2}\right) \omega_{e}{ }^{2}+k_{h}(1+s) \omega_{e}\right] \Phi_{m}{ }^{2}
$$

Correspondingly:

$$
P_{c u_{s}}=3 R_{s} I_{s}^{2}
$$




$$
\begin{gathered}
P_{c u_{\_} r}=3 R^{\prime}{ }_{r} I^{\prime}{ }^{2} r \\
\mathrm{P}_{\mathrm{cu}}=\mathrm{P}_{\mathrm{cu}_{\_} \mathrm{r}}+\mathrm{P}_{\mathrm{cu}_{-} \mathrm{s}} \\
P_{f w}=C_{f w} n_{r}{ }^{2}
\end{gathered}
$$

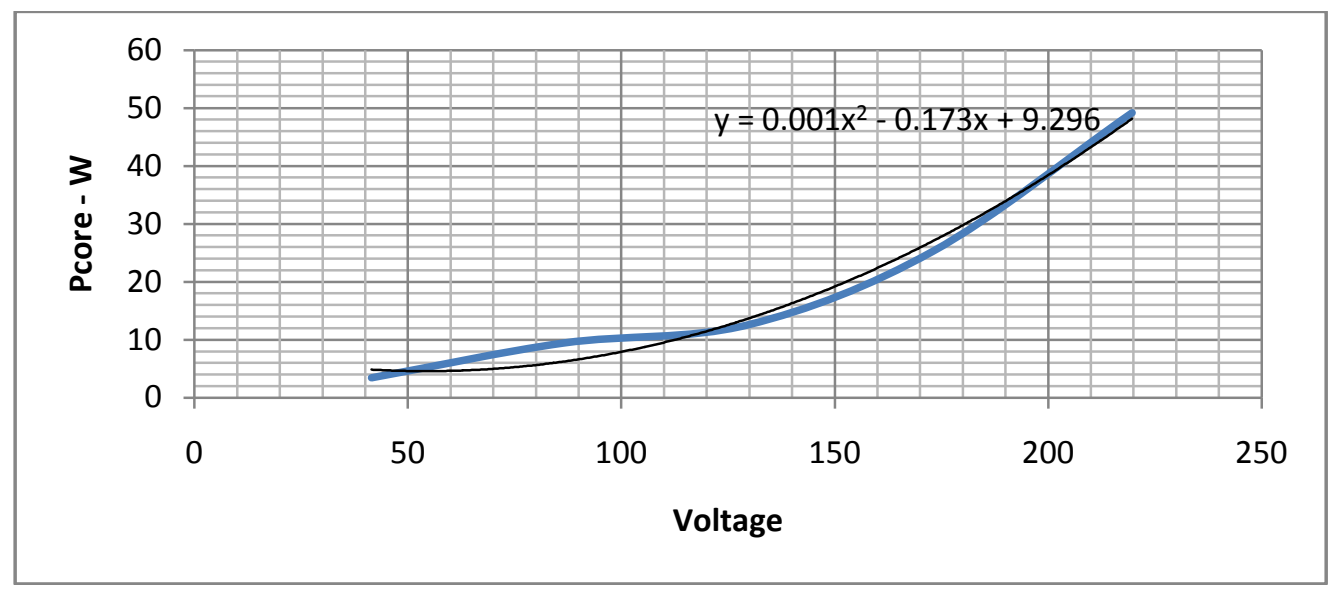

Fig. 5. In figure above the core (iron) power losses can be related to the voltage level.

\section{Inverter Drive Technique}

A commercial inverter drive for ac motor control was used. The drive is connected to the network (single phase). The is a simple rectifier that provides a dc bus at $320 \mathrm{~V}(=230 * \operatorname{sqrt}(2))$. The inverter used the vector control technique in order to produce the desired Voltage and frequency on the three phase output.

The various strategies for controlling induction motors provide good steady state response but low dynamic response [8-9].

The reason why the dynamic response is low is that the magnetic gap flow coupling deviates from the specified value. Variations in the magnetic flow must be controlled by the size and frequency of the phase currents of the stator and the rotor, and by their instantaneous phase to be as small as possible deviation of the phase and magnitude of the flow in the gap.

The oscillations of the gap flow causes vibrations in the electromagnetic torque and, if not controlled, causing oscillations in the speed, which is undesirable in many demanding applications.

As in dc motors, and so on ac, it is possible to control both the flow of power and torque. The stator current vector may be analyzed along the rotor flux. The component parallel to the rotor flux corresponding to the current producing the field. This requires, however the position of the rotor flux at any time. If possible, control of ac motors is much like the corresponding control in dc separately excited motors. 
- measure of the stator current vector: $i_{s}=\sqrt{\left(i_{q s}^{e}\right)^{2}+\left(i_{d s}^{e}\right)^{2}}$

- Angle of the vector of the stator current : $\theta_{s}=\tan ^{-1}\left\{\frac{i_{q s}^{e}}{i_{d s}^{e}}\right\}$

- $i_{q s}^{e} \quad \kappa \alpha r i_{d s}^{e}$ are the currents in the $\mathrm{d}$ and $\mathrm{q}$ axes of the synchronous rotating reference system resulting from the projection of the stator current vector in the $\mathrm{d}$ and $\mathrm{q}$ axes .

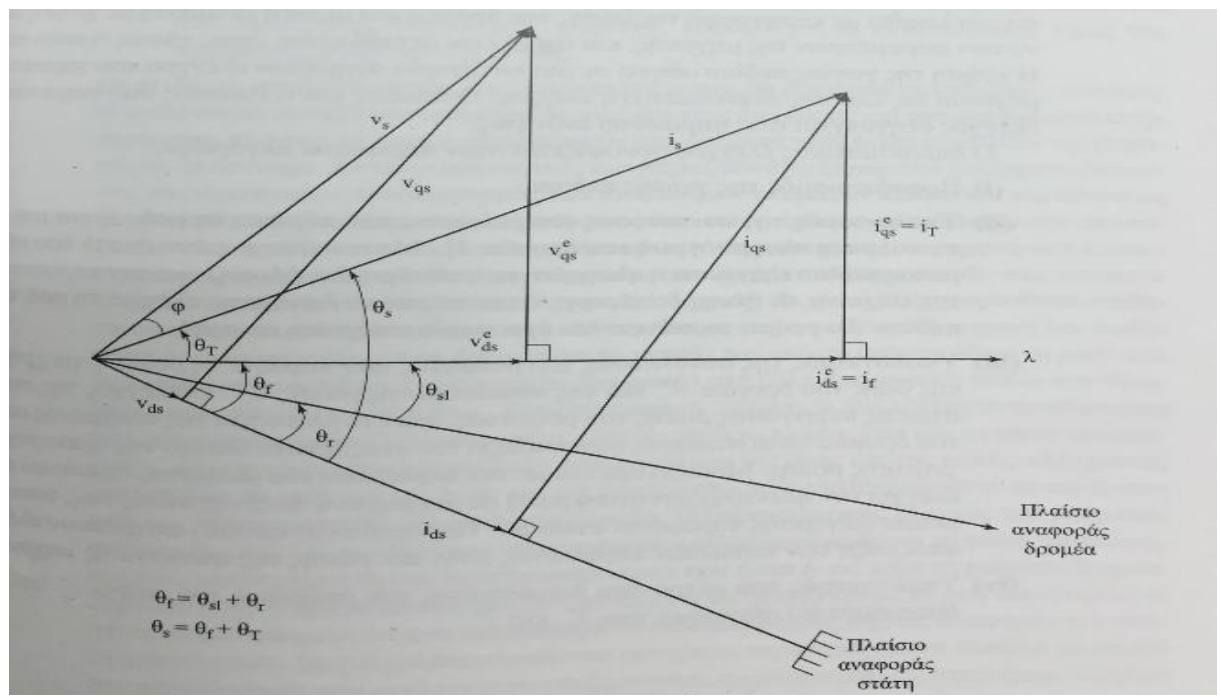

Fig. 6. Vectors for vector control technique

The figure above shows that the magnitude of the stator current vector remains constant regardless of the choice of the reference system. The illustration is the power producing flow $\mathrm{lr}$ and torque Te of the rotor. The current component that produces the flow of the rotor must be in phase with 1r. The if component is generating the field and the transverse component iT produces torque. The if and iT have only components dc in the stationary state because the relative speed relative to that of the rotor field is zero: the vector of braided rotor flow has a velocity equal to the sum of the rotor speed and the slip and is equal to synchronous speed. The orientation of the vector of braided flow cursor $\mathrm{lr}$ dictates to $\theta \mathrm{f}=\theta \mathrm{r}+\theta \mathrm{sl}$

We assume that the current components that produce flux and torque are components dc. Therefore it is ideal to be used as control variables.

Prerequisite for the implementation of vector control is to record the instantaneous position of the vector of the rotor flux thf, with

$$
\theta_{f}=\int\left(\omega_{r}+\omega_{s l}\right) d t=\int \omega_{s} d t
$$




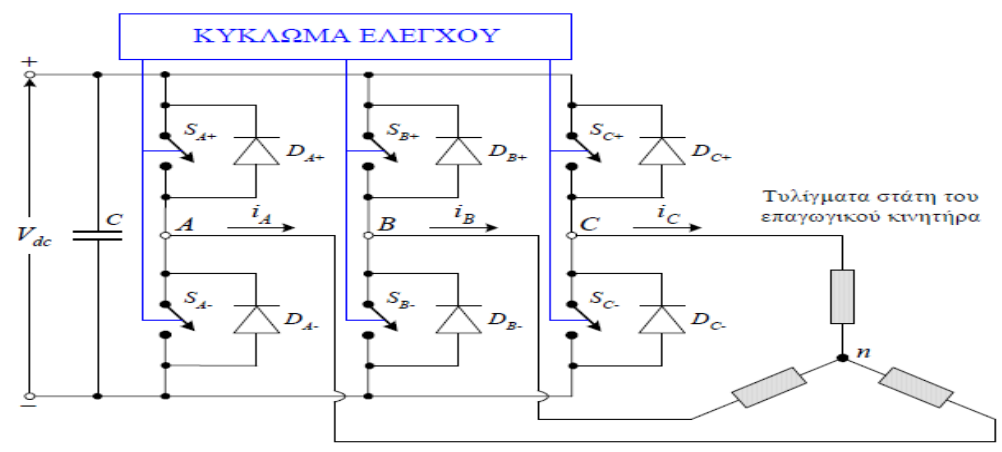

Fig. 7. Inverter equivalent circuit

The whole idea of the well known vector control technique is to drive the 3 phase ac motor as dc motor by the use of the feedback control. PWM technique is used for firing the power switching components in the appropriate timing.

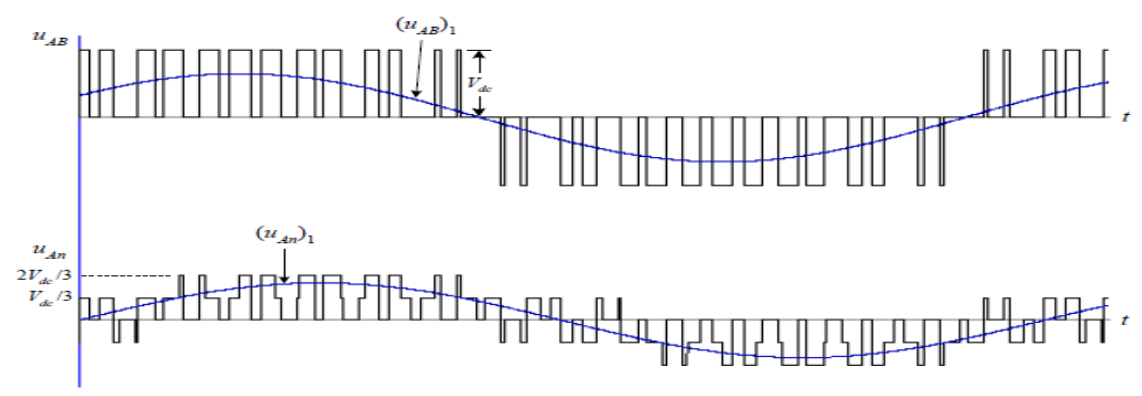

Fig. 8. PWM technique for an harmonic signal production

\section{Testing scenarios - Results}

Specific scenarios of loading the motor were investigated. At first there was a load test without inverter drive, just connected to the network with nominal voltage and frequency. This scenario was the base one.

\begin{tabular}{|c|c|c|c|c|c|c|c|c|c|}
\hline$n(r p m)$ & Pin (W) & $I(A)$ & Vло $\lambda(\mathrm{V})$ & Vф$\alpha \sigma(V)$ & kgm & $\mathrm{T}(\mathrm{Nm})$ & $\cos \Phi$ & Pout (W) & $\%$ synt_ap \\
\hline 1498 & 130 & 2,1 & 234,6 & 135,450 & 0,027 & 0,265 & 0,152 & 41,547 & 31,959 \\
\hline 1458 & 550 & 2,5 & 227,2 & 131,178 & 0,272 & 2,670 & 0,559 & 407,612 & 74,111 \\
\hline 1445 & 620 & 2,75 & 224,4 & 129,561 & 0,350 & 3,433 & 0,580 & 519,400 & 83,774 \\
\hline 1429 & 820 & 3 & 220,8 & 127,483 & 0,418 & 4,100 & 0,715 & 613,525 & 74,820 \\
\hline 1415 & 900 & 3,25 & 219,8 & 126,905 & 0,457 & 4,482 & 0,727 & 664,028 & 73,781 \\
\hline 1400 & 1000 & 3,5 & 217,3 & 125,462 & 0,525 & 5,149 & 0,759 & 754,838 & 75,484 \\
\hline
\end{tabular}




\begin{tabular}{|c|c|c|c|cccccc|}
\hline Pcus (W) & Pcore(W) & Prot(W) & S & \multicolumn{3}{c|}{ Pag(W) } & Pcure(W)Pconv(W)'out_th(W a\%_th & T_th \\
\hline 52,038 & 50,100 & 23,569 & 0,001 & 27,862 & 0,037 & 27,825 & 4,256 & 3,274 & 0,027 \\
73,750 & 50,100 & 22,939 & 0,028 & 426,150 & 11,932 & 414,218 & 391,279 & 71,142 & 2,563 \\
89,238 & 50,100 & 22,735 & 0,037 & 480,663 & 17,624 & 463,038 & 440,304 & 71,017 & 2,910 \\
106,200 & 50,100 & 22,483 & 0,047 & 663,700 & 31,415 & 632,285 & 609,802 & 74,366 & 4,075 \\
124,638 & 50,100 & 22,263 & 0,057 & 725,263 & 41,098 & 684,164 & 661,902 & 73,545 & 4,467 \\
144,550 & 50,100 & 22,027 & 0,067 & 805,350 & 53,690 & 751,660 & 729,633 & 72,963 & 4,977
\end{tabular}

\section{Fig. 9. Measurements for base scenario}

The next scenarios that were applied on the test system were by use of an inverter drive, with $\mathrm{V} / \mathrm{F}$ ratio constant, in different varying frequencies from $20 \mathrm{~Hz}$ to $60 \mathrm{~Hz}$.

The basic idea was to measure the power loss and to investigate its variation. For low loading conditions, it is preferable to run in lower speed, with low frequency and low Voltage correspondingly. Lower speed means low mechanical losses, and lower Voltage means less magnetic - iron losses.

Below several measurements are presented:

A. $40 \mathrm{~Hz}$

\begin{tabular}{|c|c|c|c|c|c|c|c|c|c|}
\hline$n(r p m)$ & Pin (W) & $I(A)$ & Vлод(V) & Vф$\alpha \sigma(\mathrm{V})$ & kgm & $\mathrm{T}(\mathrm{Nm})$ & $\cos \Phi$ & Pout (W) & $\%$ synt_ap \\
\hline 1197 & 110 & 1,9 & 201,5 & 116,339 & 0,027 & 0,265 & 0,166 & 33,393 & 30,357 \\
\hline 1151 & 470 & 2,5 & 193 & 111,432 & 0,233 & 2,288 & 0,562 & 275,815 & 58,684 \\
\hline 1140 & 600 & 2,75 & 192,5 & 111,143 & 0,330 & 3,242 & 0,654 & 387,004 & 64,501 \\
\hline 1133 & 680 & 3 & 191,8 & 110,739 & 0,379 & 3,719 & 0,682 & 441,191 & 64,881 \\
\hline 1118 & 780 & 3,25 & 191,2 & 110,393 & 0,447 & 4,386 & 0,725 & 513,489 & 65,832 \\
\hline 1107 & 840 & 3,5 & 190,9 & 110,219 & 0,476 & 4,672 & 0,726 & 541,596 & 64,476 \\
\hline
\end{tabular}

\begin{tabular}{|c|c|c|c|ccccc|c|}
\hline Pcus (W) & Pcore(W) & Prot(W) & S & \multicolumn{1}{c}{ Pag(W) } & Pcure(W)Pconv(W)'out_th(W a\%_th & T_th \\
\hline 42,598 & 35,470 & 18,833 & 0,003 & 31,932 & 0,080 & 31,852 & 13,019 & 11,836 & 0,104 \\
73,750 & 35,470 & 18,109 & 0,041 & 360,780 & 14,732 & 346,048 & 327,939 & 69,774 & 2,721 \\
89,238 & 35,470 & 17,936 & 0,050 & 475,293 & 23,765 & 451,528 & 433,592 & 72,265 & 3,632 \\
106,200 & 35,470 & 17,826 & 0,056 & 538,330 & 30,057 & 508,273 & 490,447 & 72,125 & 4,134 \\
124,638 & 35,470 & 17,590 & 0,068 & 619,893 & 42,359 & 577,533 & 559,943 & 71,788 & 4,783 \\
144,550 & 35,470 & 17,417 & 0,078 & 659,980 & 51,148 & 608,832 & 591,415 & 70,407 & 5,102 \\
\hline
\end{tabular}

Fig. 10. Measurements for $40 \mathrm{~Hz}$ tests

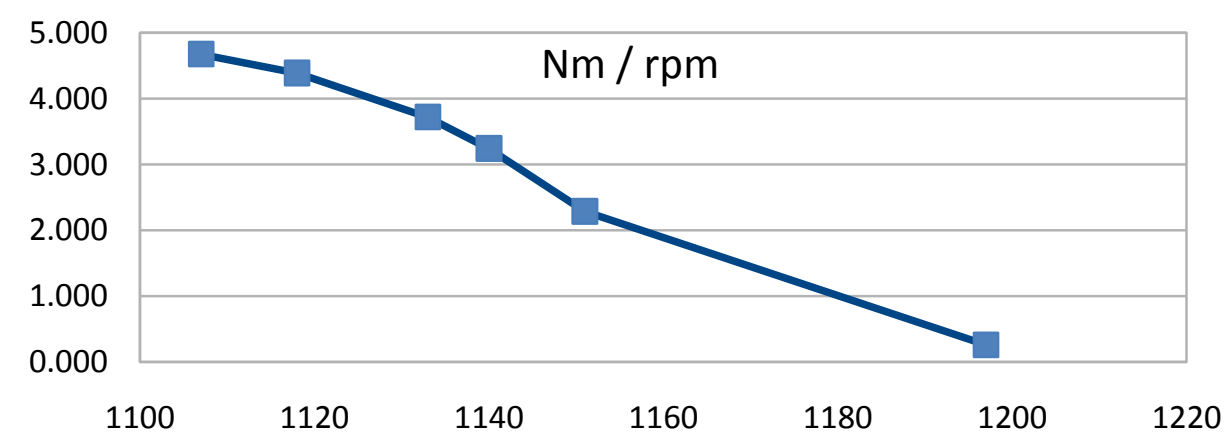

Fig. 11. Torque to rpm 


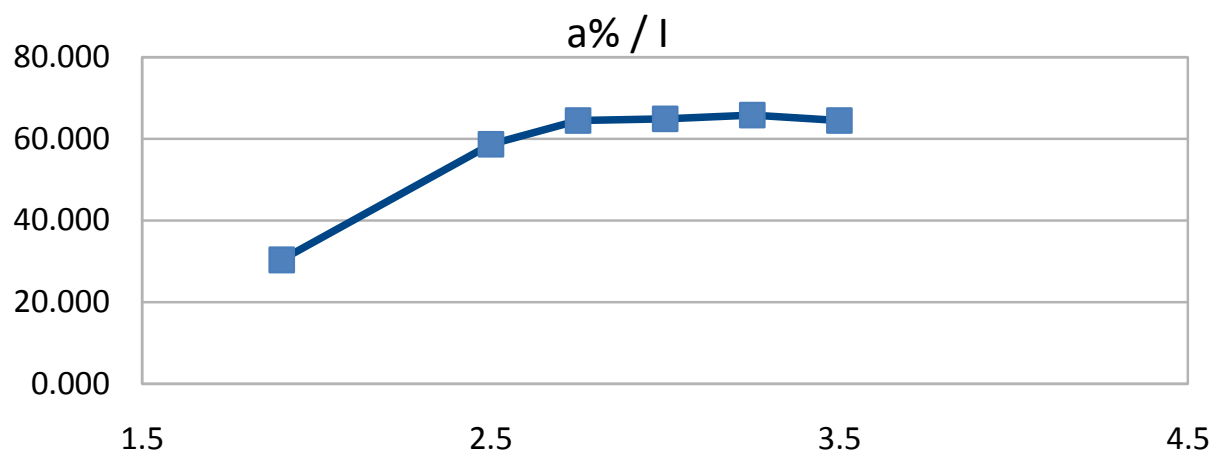

Fig. 12. Performance to current

B. $60 \mathrm{~Hz}$

\begin{tabular}{ccc|c|c|c|c|c|cc}
\hline n(rpm) & Pin (W) & I (A) & V $\pi$ o $\boldsymbol{\lambda ( V )}$ & V $\phi \alpha \sigma(V)$ & kgm & T (Nm) & cos $\Phi$ & Pout (W) $\%$ synt_ap \\
\hline 1796 & 150 & 1,6 & 237,0 & 136,836 & 0,025 & 0,245 & 0,228 & 46,122 & 30,748 \\
1755 & 450 & 2,0 & 227,1 & 131,120 & 0,194 & 1,907 & 0,572 & 350,460 & 77,880 \\
1727 & 680 & 2,5 & 222,8 & 128,637 & 0,301 & 2,956 & 0,705 & 534,547 & 78,610 \\
1710 & 790 & 2,8 & 220,8 & 127,483 & 0,360 & 3,528 & 0,751 & 631,727 & 79,965 \\
1698 & 860 & 3,0 & 219,9 & 126,963 & 0,399 & 3,909 & 0,753 & 695,110 & 80,827 \\
1681 & 970 & 3,3 & 218,2 & 125,982 & 0,428 & 4,196 & 0,790 & 738,503 & 76,134 \\
1669 & 1030 & 3,5 & 217,5 & 125,577 & 0,457 & 4,482 & 0,781 & 783,224 & 76,041
\end{tabular}

\begin{tabular}{|c|c|c|c|cccccc|}
\hline Pcus (W) & Pcore(W) & Prot(W) & S & \multicolumn{2}{c|}{ Pag(W) } & Pcure(W)Pconv(W)'out_th(W a\%_th & T_th \\
\hline 30,208 & 52,430 & 28,257 & 0,002 & 67,362 & 0,150 & 67,212 & 38,955 & 25,970 & 0,207 \\
47,200 & 52,430 & 27,612 & 0,025 & 350,370 & 8,759 & 341,611 & 313,999 & 69,778 & 1,709 \\
73,750 & 52,430 & 27,171 & 0,041 & 553,820 & 22,460 & 531,360 & 504,188 & 74,145 & 2,788 \\
89,238 & 52,430 & 26,904 & 0,050 & 648,333 & 32,417 & 615,916 & 589,012 & 74,558 & 3,290 \\
106,200 & 52,430 & 26,715 & 0,057 & 701,370 & 39,744 & 661,626 & 634,911 & 73,827 & 3,571 \\
124,638 & 52,430 & 26,448 & 0,066 & 792,933 & 52,422 & 740,511 & 714,063 & 73,615 & 4,057 \\
144,550 & 52,430 & 26,259 & 0,073 & 833,020 & 60,625 & 772,395 & 746,136 & 72,440 & 4,269 \\
\hline
\end{tabular}

Fig. 13. Measurements for $60 \mathrm{~Hz}$ tests

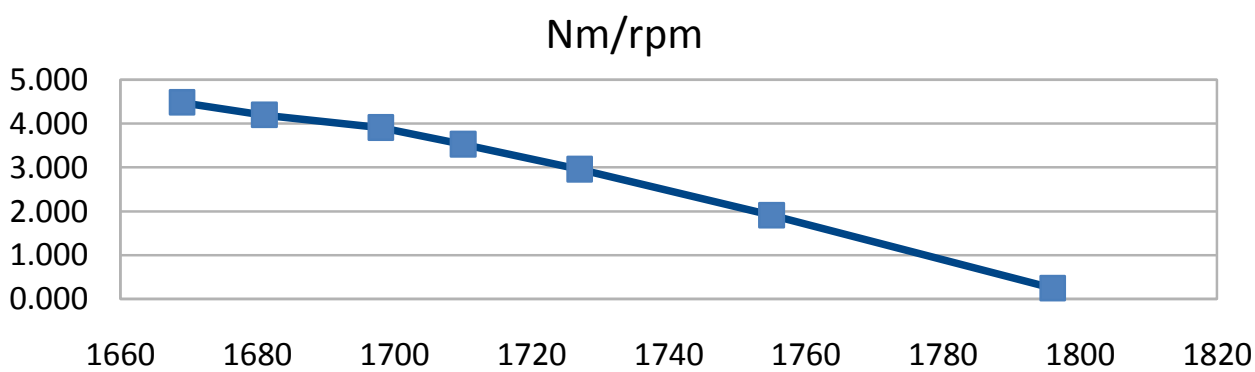

Fig. 14. Torque to rpm 


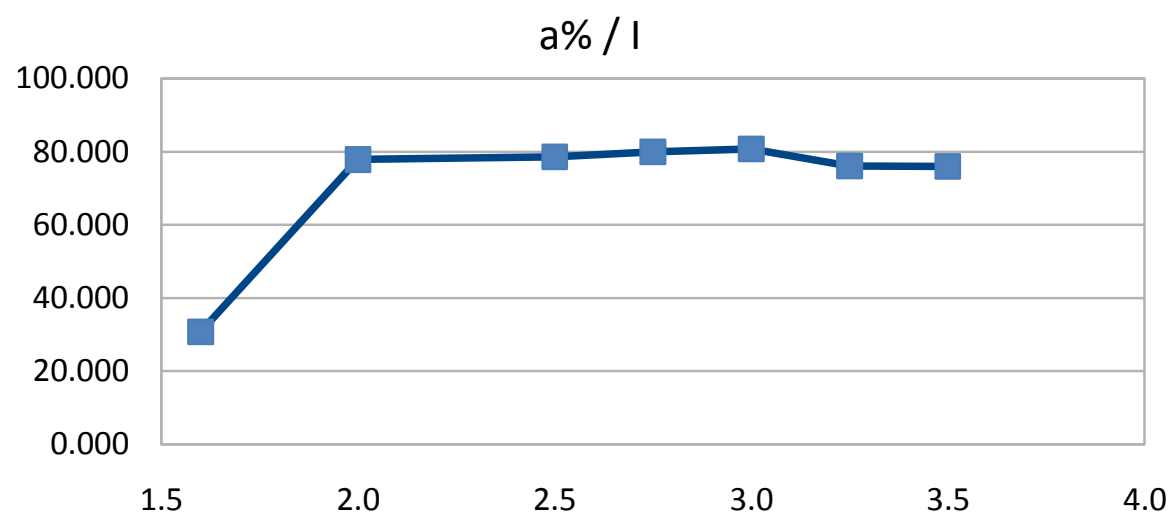

Fig. 15. Performance to current

Y: Torque $-\mathrm{X}$ : rpm

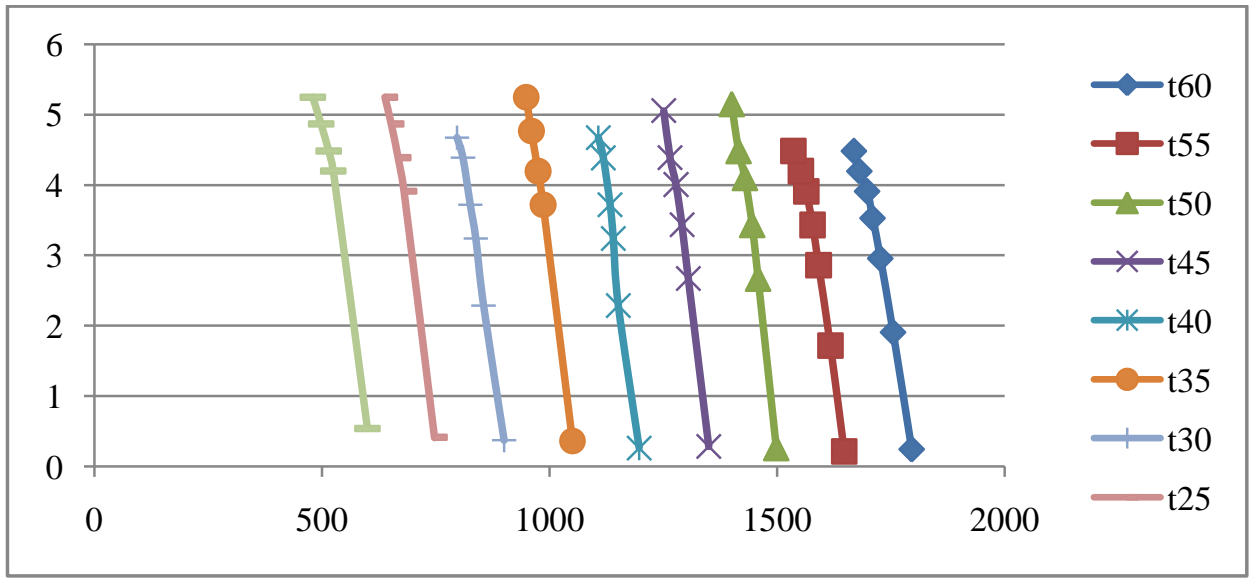

Fig. 15. Torque to rpm

In the above graph it is obvious that practically in all the frequency levels of the motor, the torque response is quite satisfactory. So in applications where high torque is necessary, the motor can operate also in lower levels of frequency and hence less power consumption. 


\section{Y: Efficiency - X: rpm for different frequencies}

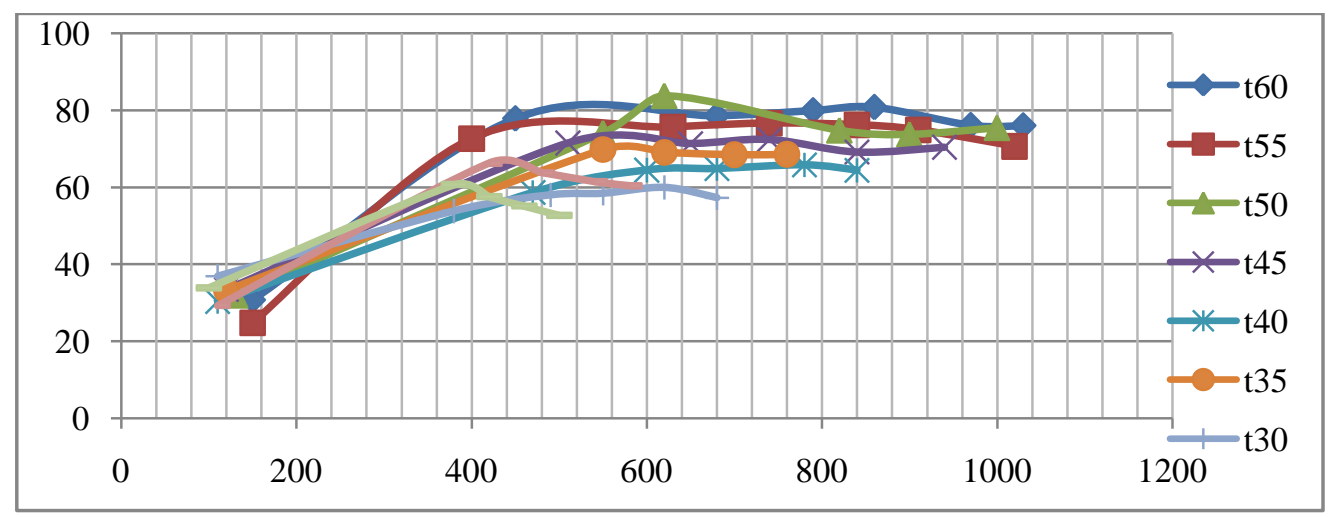

Fig. 16. Performance to rpm

From the above chart we see that the motor efficiency at frequencies $45 \mathrm{~Hz}$ to $60 \mathrm{~Hz}$ is quite satisfactory. We also note that the performance at different frequencies of operation is relatively stable, at a high level, while the motor power consumption range descends. So we understand that driving the engine at these frequencies, we can have high efficiency and low power consumption.

$$
\mathrm{Y}: \cos \varphi-\mathrm{X}: \mathrm{rpm}
$$

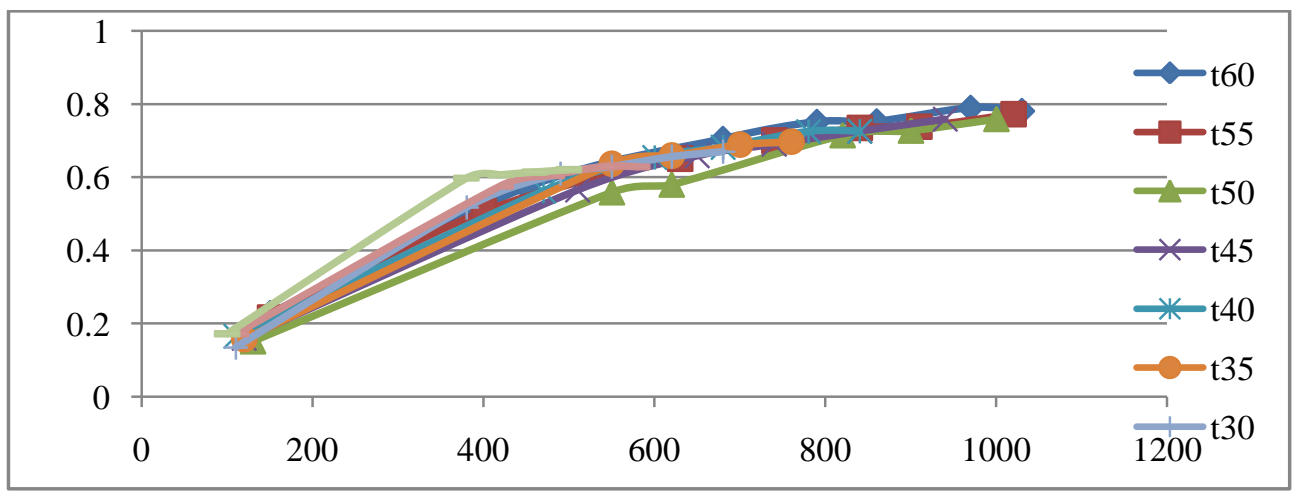

Fig. 17. Cos $\varphi$ to rpm

Observing the graph above, we see that it is possible to have a drive system of a power factor of about 0.70 , driving the motor at all frequency levels in our tests. Thus, in applications where control of motor speed is necessary, on one hand we control the speed and on the other hand we ensure a good level in power factor. 


\section{Discussion and Conclusions}

The work described in this paper helped significantly to understand the general operation of the three-phase induction motors driven by frequency converter. We found that we can drive a system at different frequency levels without greatly lost torque. We can also save energy by operating the lower frequencies where but we equally satisfy the nominal level of performance.

It is also worth to mention about the user friendly character of the inverter to control the motor speed, the smooth starting and the high-efficiency in all frequency ranges.

\section{References}

[1] W. Leonhard, "Controlled AC Drives, a Successful Transfer from Ideas to Industrial Practice," Control Engineering Practice, Vol. 4, No. 7, 1996, pp. 897-908. doi:10.1016/0967-0661(96)00087-1

[2] G. C. D. Sousa, B. K. Bose and J. G. Cleland, "Fuzzy Logic Based on-Line Efficiency Optimization Control of an Indirect Vector-Controlled Induction Motor Drive," IEEE Transactions on Industrial Electronics, Vol. 42, No. 2 , 1995, pp. 192-198. doi:10.1109/41.370386

[3] H. R. Andersen, C. B. Rasmussen, E. Ritchie and J. K. Pedersen, "Efficiency Comparison of Electrical Motors for Energy Optimized Variable Speed Low Power and Low Cost Household Equipment," 6th European Conference on Power Electronics and Applications, Seville, 1995, pp. 33813386.

[4] F. C. Lin and S. M. Yang, "On-Line Tuning of an Efficiency-Optimized Vector Controlled Induction Motor Drive," Tamkang Journal of Science and Engineering, Vol. 6, No. 2, 2003, pp. 103-110.

[5] A. K. Sharma, R. A. Gupta and Laxmi Srivastava. "Implementation of Neural Network in Energy Saving of Induction Motor Drives with Indirect Vector Control," Journal of Theoritical and Applied Information Technology, Vol. 5, 2008, pp. 774-779.

[6] Stephen J. Chapman, electric-machinery-fundamentals-5th-ed

[7] http://electrical-engineering-portal.com/three-phase-induction-motorsoperating-principle

[8] http://www.electricaleasy.com/2014/02/speed-control-methods-of-inductionmotor.html

[9] http://www.electrical4u.com/speed-control-of-three-phase-induction-motor 